Discussion Paper

\title{
A Discussion of the Synergy and Divergence between Lean Six Sigma and Person-Centred Improvement Sciences
}

\author{
${ }^{1,2,4}$ Seán Paul Teeling, ${ }^{2}$ Jan Dewing and ${ }^{2,3}$ Deborah Baldie \\ ${ }^{1}$ UCD School of Nursing Midwifery and Health Systems, UCD, Dublin, D04 V1W8, Ireland \\ ${ }^{2}$ Queen Margaret University, Centre for Person-Centred Practice Research, Division of Nursing, \\ School of Health Sciences, Queen Margaret University Drive, Musselburgh, East Lothian EH21 6UU, UK \\ ${ }^{3}$ NHS Tayside, Dundee DD91SY, UK \\ ${ }^{4}$ Mater Misericordiae University Hospital, Dublin, D07 AX57, Ireland
}

\author{
Article history \\ Received: 11-01-2020 \\ Revised: 16-03-2020 \\ Accepted: 09-04-2020 \\ Corresponding Authors: \\ Seán Paul Teeling \\ UCD School of Nursing \\ Midwifery and Health Systems, \\ UCD, Dublin, D04 V1W8, \\ Ireland \\ Email: sean.p.teeling@ucd.ie
}

\begin{abstract}
Background: This paper discusses if and how the improvement sciences of Lean Six Sigma and person-centred approaches can be melded or blended in the health care context. The discussion highlights the relationship between each approach to improvement science in terms of their respective purposes, intentions and probable outcomes; positioning these as either synergies or divergences. Comparison of the key theoretical and methodological principles underpinning each approach to improvement is also considered and implications for future practice, policy and research are drawn out. The discussion is informed by part of the findings of a realist review of relevant literature.
\end{abstract}

Conclusions: Lean Six Sigma as a process improvement methodology appeals to a wide range of stakeholders in healthcare internationally. Four key synergies and three key divergences between Lean Six Sigma and person-centred approaches were found. The discussion here highlights the need for further research into Lean Six Sigma implementation and its possible contribution to developing person-centred cultures.

Impact: Adoption of Lean Six Sigma in health care by stakeholder groups, external to nursing, has been taking place. At the same time there has been a loss of Lean's original intention of respect for people in favour of a technical efficiency focus on reducing waste and variation. Our findings of four key synergies and three key divergences between both approaches indicate where synergies can be maximised and divergence narrowed to improve implementation and enhance methodological coherence. Researchers, policy makers and practitioners should be aware that use of Lean Six Sigma alone may have a limited impact on developing personcentred care and culture. Use of Lean combined with person-centred approaches may appeal to a wider range of stakeholders. Yet, their combined use and effectiveness has not as yet been evaluated.

Keywords: Lean, Lean Six Sigma, Process Improvement, Personhood, Person-Centred Care, Person-Centred Cultures, Six Sigma, Kaizen.

\section{Introduction}

This article discusses if and how the improvement sciences of Lean Six Sigma and person-centred care can be melded or blended in a health care context. The discussion highlights the relationship between each approach in terms of their respective purposes, intentions and probable outcomes; positioning these as either synergies or divergences. Comparison of the key theoretical and methodological principles underpinning each approach to improvement is also considered and implications for future practice, policy and research are drawn out.

Person-centredness is, according to Dewing and McCormack (2016), in ascendancy as a particular type of approach and culture that applies to everyone in the organisation, staff, patients and families alike. McCormack and McCance (2017) describe personcentredness in healthcare as the practice of forming and 
fostering healthful relationships between service users, families and care providers with the intent of improving and innovating the experience of healthcare for all. It should be noted that this definition explicitly includes innovation not just improvement. McCance et al. (2011) amongst others, suggest that the focus on person-centredness in healthcare reflects society's need to address ongoing issues of service delivery imbalance and the requirement to move from a medical ethos to a more humanised and collaborative one. This article discusses the compatibility of Lean Six Sigma (as an improvement methodology) with person-centred approaches. It outlines the divergences and synergies between both and provides recommendations on how to minimise the divergence whilst maximising the synergies of Lean Six Sigma with the aims of personcentredness - to improve and innovate with the ultimate purpose of developing cultures of person-centredness and its associated outcomes.

\section{Background}

At present there exists a divide between innovative approaches to transforming care experience and services and improvement based methods that focus on efficiency and clinical outcomes. Healthcare systems internationally are working under increasing demand to use finite resources with greater efficiency. Combined with a continued focus on patients' clinical outcomes, this tends to favour Lean Six Sigma as an improvement methodology. However, increasingly there is now a focus on a better staff and patient experience (Nicosia et al., 2018; Moraros et al., 2016) that favours person-centred approaches. Powell et al. (2009) recognise that improvement in healthcare quality is a challenge for healthcare staff; much quality improvement implementation places responsibility on those planning and delivering patient care to deliver process improvement. Lean Six Sigma has been in use in healthcare since 2001 in the UK and 2002 in the USA and is defined as one of the most internationally popular process improvement methodologies in healthcare services (Radnor and Osborne, 2013; Williams, 2015; Jorma et al., 2016). Similarly, person-centred approaches have risen in popularity since the millennium with political and policy intentions now widely advocating person-centredness should be at the heart of the health system (Nolte, 2017; ICN, 2019). Lean Six Sigma combines both Lean and Six Sigma methodologies to minimise non-value add activity and unwanted process variation. Lean Six Sigma outcomes have been broadly categorised as having impact on health outcomes, processes of care, quality of care, finances and patient and staff satisfaction (Deblois and Lepanto, 2016). Working to improve process based on customer requirements and staff engagement are espoused as important factors in the application of Lean Six Sigma. Internationally, whilst there is a body of research on Lean and Six Sigma, there is little research on Lean Six Sigma and its specific influence on person-centredness. Given the popularity of Lean and Six Sigma as process improvement methodologies with potential for cost saving and increased efficiency in healthcare alongside the continuing need for development of person-centred cultures, we believe it is of international importance for nursing that synergies, divergences and the potential between/of both to be combined/used in complementary ways is examined.

Many Lean Six Sigma interdisciplinary healthcare improvement projects include nurses (Collins and Muthusamy, 2007; Nelson-Peterson and Leppa, 2007; Ballé and Régnier, 2007; O’Neill et al., 2011; Fillingham, 2008; O'Hora et al., 2015; Kieran et al., 2018; Creed et al., 2019; Teeling et al., 2019). Lean Six Sigma claims to use a bottom up, top down approach, which means that healthcare staff such as nurses can examine their own work processes, collect and analyse their own data using rapid root cause analysis and implement their own solutions (Jorma et al., 2016). Johnston (2013) suggest that nursing is a profession ideally suited to Lean Six Sigma deployment as its members have extensive experience of being part of and leading interdisciplinary teams, are patient focused and can view the healthcare system from the patients' viewpoint. Conversely, McCormack et al. (2015) state that healthcare delivery needs to move from a culture reliant of evaluating particular types of outcome and re-orientate to a person-centred evaluation framework (Berwick, 2015; McCormack, 2015), that primarily values and takes as its starting point peoples experiences. Given, these seemingly very different values, it leads to asking if the two approaches can be combined at all.

\section{Methods}

As the basis for this discussion, we draw from one part of the findings in a structured review of the relevant literature carried out between August 2016 to September 2017. For the review, CINAHL, EBSCOhost, Proquest, Medline and PubMed databases were used to identify research studies examining Lean Six Sigma, person-centred care and person-centred cultures or a combined use of both Lean Six Sigma and person-centred approaches in healthcare. These were research based rather than discursive opinion and encompassed both empirical and conceptual studies. Three strands were identified for search within the literature with a focus on the following keywords:

1. Lean, Six Sigma, Process Improvement

2. Person-centredness, care and cultures. Patientcentredness

3. A combination of the keywords from strands 1 and 2 to refine the search

Across all three strands, reference lists of retrieved articles were examined for the key search terms in their 
titles and affiliated searching of the reference lists of retrieved items was also conducted to identify further research articles not identified through the keyword searches. The following inclusion and exclusion criteria were applied in order to narrow the search results:

1. Inclusion of work published relating to Lean Six Sigma in healthcare in the English language after 2000; the rationale for this being that Lean Six Sigma was first introduced into healthcare settings early in the decade and up to 2017
2. Inclusion of work relating to criterium 1 (Lean Six Sigma) that additionally discuss the concept of patient-centred care but also reference person-centred care or person-centred cultures.

3. Inclusion of work relating to person-centred care and person-centred cultures cultures from 1995 to 2017; the rationale for this being that it is a period of 'strong academic momentum and practice emergence' (Edvardsson et al., 2010)

4. Inclusion of peer-reviewed, full text journal articles with complete bibliography

PRISMA 2009 Flow Diagram

From: Moher D, Liberati A, Tetzlaff J, Altman DG, The PRISMA Group (2009)

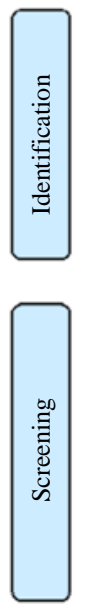

Records identifies through database searching Strand $1(\mathrm{n}=258)$ Strand $2(\mathrm{n}-1600)$

Strand $3(\mathrm{n}=22)$

Total records identified $(n=1880)$
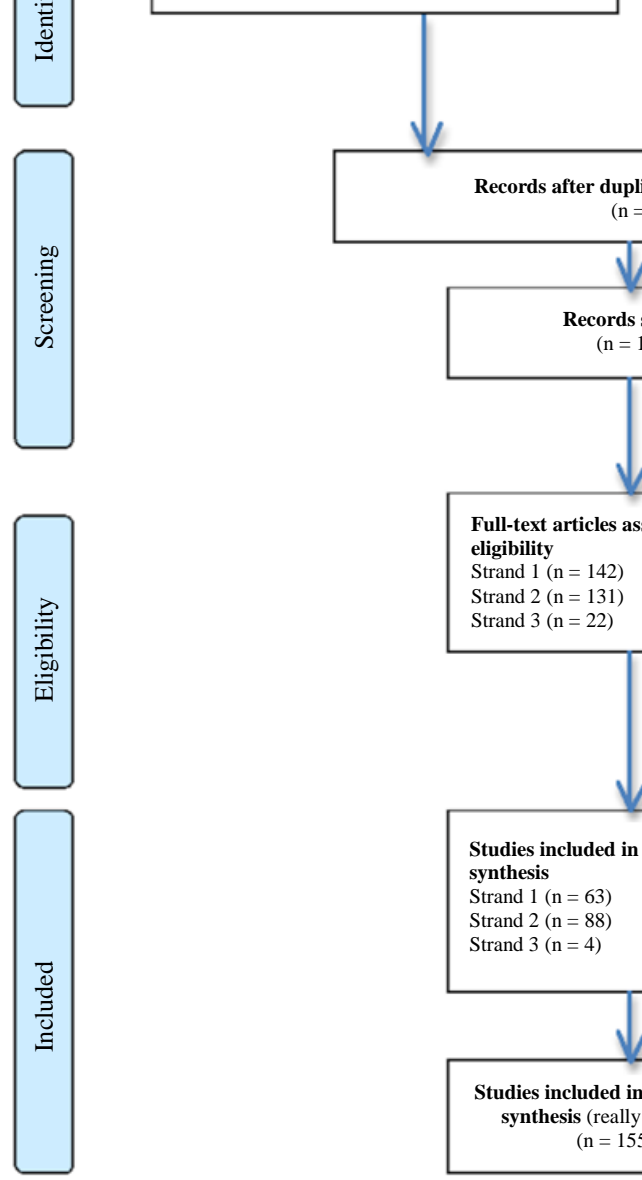

Records after duplicates $(\mathrm{n}=\mathbf{0})$ removed $(\mathrm{n}=1880)$
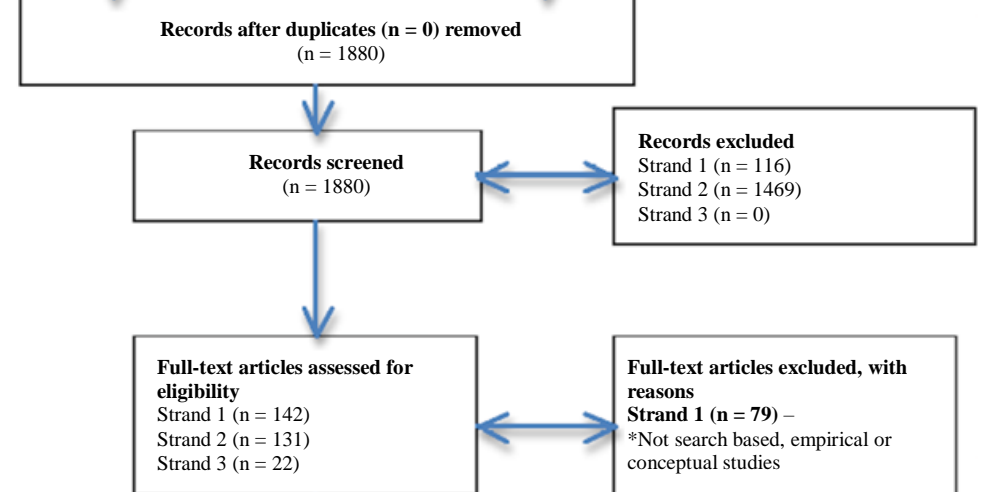

Full-text articles excluded, with reasons

trand $1(n=79)$ -

*Not search based, empirical or conceptual studies

Strand $2(n=43)$

*Did not discuss PCC or PCCu *Did not discuss concept of patientcentred care (37)

*Did not discuss patient-centred care in relation to both PCCa \& LSS

Strand $3(n=18)$

Studies included in qualitative synthesis

Strand $1(n=63)$

Strand $1(\mathrm{n}=63)$

Strand $2(\mathrm{n}=88)$

Strand $3(n=4)$

*Did not discuss lean specifically in

the context of PCCa/PPCu

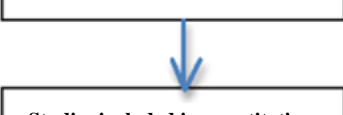

tudies included in quantitative synthesis (really synthesis) $(\mathrm{n}=155)$

Abbreviations:

LSS = Lean Six Sigma

$\mathrm{PCCa}=$ Person-centred care

$\mathrm{PCCa}=$ Person-centred care
$\mathrm{PCCu}=$ Person-centred culture

Fig. 1: Search summary for realist review 
The above criteria facilitated a comprehensive and quality yield of papers for review, summarised in Fig. 1, which provides a background to our discussion.

In the review we sought to understand more about the use of Lean Six Sigma and person-centred approaches; where the distinct intention was to develop a person-centred culture; to compare the principles underpinning each and identify the ways in which the two approaches to improving and innovating health care have or could work synergistically for the benefit of staff, patients and public. As an under researched area, our discussion creates an overview of what is currently known about the relationship between both approaches.

We found that there is little published on Lean Six Sigma in healthcare before 2000, with most output commencing in 2004 and increasing steadily to 2018. This probably reflects the fact that Lean Six Sigma was only introduced to healthcare (with little underpinning applied evidence) in the early part of the millennium. Most of the evidence we reviewed (Fig. 1) was empirical case study or survey based $(60 \%)$, the remainder being literature review $(40 \%)$, with the majority of empirical studies conducted predominantly in the USA.

Despite the increase in the volume of literature on Lean Six Sigma in healthcare between 2000 and 2018, very few studies have examined its contribution alongside person-centred approaches and the impact on person-centred care and person-centred cultures. In total, 22 publications referred to person-centredness when discussing Lean Six Sigma use, however only 4 publications (Veech, 2004; Kelly, 2013; Colldén et al., 2017; Dunsford and Reimer, 2017) specifically discuss Lean Six Sigma and person-centredness and only 1 of these articles focused on nursing.

\section{Discussion}

Following on from our review of the literature, this discussion establishes the current position of both Lean Six Sigma and person-centred approaches through four synergies and three divergences. We conclude with offering implications for how both approaches can be better combined to improve staff and patient care experiences.

\section{An Overview of Lean Six Sigma and Person- Centredness}

Lean is described as a process improvement approach that consists of the elimination of waste (steps that do not add value in the eyes of the customer) to improve the flow of people, information or goods. In healthcare there can be both internal customers (e.g., Nurse orders a blood test and becomes a customer of the Pathology service) and external customers, (e.g., patients, family and friends) (Zidel, 2006; Aherne and Whelton, 2010). Six Sigma is a data driven process improvement methodology designed to improve process capability and enhance process throughput through the introduction of improvement projects (Bisgaard and Freiesleben, 2000; Pande et al., 2002; Rath and Strong, 2002; George et al., 2005). For example, Six Sigma has shown positive outcomes including reducing time to be admitted in the Emergency Department, reducing errors in diagnoses and reduction in surgical errors (Antony, 2007). A hybrid of Lean and Six Sigma (Lean Six Sigma) first appears in the literature from 2010 onwards. Although, Abu Bakar et al. (2015) suggest Lean and Six Sigma integration for project delivery started in 2002. A combination of Lean, to eliminate Non Value Add (NVA) and Six Sigma to eliminate variation that contributes to NVA, are what constitutes Lean Six Sigma. Synergies between both methodologies, as identified by us, are provided in Table 1.

Further, Lean Six Sigma has demonstrated some positive outcomes in healthcare (De Souza, 2009; Mazzocato et al., 2010; Yeh et al., 2011; Burgess and Radnor, 2013). Table 2 categorises outcomes into those for the organisation, patients and staff.

Table 1: Synergies between Lean and Six Sigma

\begin{tabular}{lll}
\hline Commonality & Lean & Six sigma \\
\hline Customer Focus & $\checkmark$ & $\checkmark$ \\
Management commitment required & $\checkmark$ & $\checkmark$ \\
Employee engagement paramount & $\checkmark$ & $\checkmark$ \\
Seeks to improve process & $\checkmark$ & $\checkmark$ \\
Cross functional teams & $\checkmark$ & $\checkmark$ \\
Productivity/Cost saving benefit & $\checkmark$ & $\checkmark$ \\
Dedicated/Structured approach & $\checkmark$ & $\checkmark$ \\
Adapted from Vijaya Sunder (2013) & & \\
\hline
\end{tabular}

Table 2: Outcomes of Lean Six Sigma use

\begin{tabular}{lll}
\hline Organisational Outcomes* & Patient outcomes & Employee outcomes \\
\hline Earlier admission & Satisfaction & Satisfaction \\
Turn Around Times (TAT) & Mortality rate & Time to spend with patient \\
Arrival to Triage time & Readmission rate & Professional development \\
Wait time to physician & Informed & Reduced overtime \\
Consult wait time & & Staff engagement \\
Discharge rates & & \\
Length of Stay (LOS) & & \\
\hline *As relates to Key Performance Indicators (KPIs) & &
\end{tabular}


At a patient level outcomes tend to be at the micro level and range from reduced wait times and faster access to treatment in Emergency Departments (Fillingham, 2008; Cookson et al., 2011; Mazzocato et al., 2014) and improved patient outcomes in Cardiac Units (McConnell et al., 2013) to earlier access to diagnostics in Radiology Departments (Fillingham, 2008; Tolga Taner et al., 2007; Teichgräber and de Bucourt, 2012; O'Hora et al., 2015). While, a useful contribution, they do not constitute the entirety of a good care or work experience. Further, Black (2009) claims that Lean Six Sigma does not fully consider the complexities of social interactions in health care contexts.

As far back as 2004, McCormack notes the complexity of person-centred care and the need for nurses to shift beyond technical competence to authentic, humanising nursing practices. An ontological understanding is integral to person-centred care as it is primarily about a way of being, although pressures of every day nursing may not always fully permit this value-based approach to prevail. McCormack and McCance (2017) describe person-centredness in healthcare as a culture and in the following way:

\begin{abstract}
"an approach to practice established through the formation and fostering of healthful relationships between all care providers, service users and others significant to them in their lives. It is underpinned by values of respect for persons (personhood), individual right to self-determination, mutual respect and understanding. It is enabled by cultures of empowerment that foster continuous approaches to improvement and innovation such as practice development"

(Adapted from McCormack and McCance, 2017, p.3).
\end{abstract}

Person-centred approaches generally comprise an appreciation for all participants in the delivery and receipt of healthcare. For example, work in a regional aged care service in New South Wales, Australia involved nurses in the design and content of a programme to enable them to feel empowered in leading their teams, with demonstrable impacts on workplace culture (Marriott-Statham et al., 2018). McCormack et al. (2010) discuss an evaluation of part of a National programme of practice development undertaken in residential care settings for older people in Ireland. The findings illustrate the emphasis that person-centred approaches place on staff experiences of participating in care giving. In this case through recognising the importance of effective teamwork, time and workload management and relationships among staff to enable the creation of a democratic and inclusive culture that in itself facilitates space for the creation of person-centred relationships. Jones (2017) set out three key principles for any person-centred methodology: (i) Attentiveness and dialogue; (ii) Empowerment and participation and (iii) Reflexivity (relating to reflection on the process, context and outcomes of research). In addition to the benefits for staff of person-centred practice, studies have also illustrated that the principles of person-centred care can impact on the experience of people receiving care. $\mathrm{Li}$ and Porock (2014) in a review of nine studies of personcentered care of people with dementia in long term care settings, found significant effect on reducing pychotropic drug use and decreasing behavioural symptoms. Personcentred approaches lead to more involvement by people in their own care and associated improved outcomes (such as reduced blood pressure) and to increased satisfaction among the healthcare staff about the quality of the care they deliver (Mead and Bower, 2002; McMillan et al., 2013).

Kelly (2013) contends that Lean Six Sigma methodology does not support person-centred care; as its quest for standardisation is about the organisations need to produce efficiencies. However, we found this is a broad statement in a limited and short overview of Lean Six Sigma and person-centred care. A general feature of much of the person-centred literature is that culture transformation is needed to achieve person-centred care. While this culture change may include improvement initiatives, these are not enough on their own (Manley and McCormack, 2008; McCormack et al., 2013; McCormack and McCance, 2017). We believe that for there to be any coherent approach in developing an integrative approach to improvement using both Lean Six Sigma and person-centred care, that the synergies and divergence between both methodologies are important in informing this discussion.

\section{Synergy}

\section{Respect for Persons}

Respecting the needs and the preference of the individual is a key process of person-centred care (Moore et al., 2016) and respect for persons is central to person-centredness (McCormack, 2003). The foundational concept for Lean Six Sigma is the concept of 'Kaizen' (good change) and it has its origins in the three main features of the Japanese management philosophy, which are: harmony and loyalty, consensus in decision-making and employment for life. These three features are all included in the Japanese concept of respect for people (Suárez-Barraza et al., 2011). This concept of Kaizen respect has synergies with personcentred theory that has an emphasis on developing person-centred cultures through collaborative, inclusive and participatory approaches (Dewing and McCormack, 2017). Guimarães and De Carvalho (2012) claim that 
when American firms began to utilise Japanese management styles, the focus was sometimes only on the continuous improvement aspect, with the cultural aspect of Kaizen not actually understood and was forgotten about. Suárez-Barraza et al. (2011) suggest that this focus on continuous improvement and not on Kaizen as a management philosophy, underpinned by principles and values, is detrimental to staff engagement in any Lean based process improvement.

The concept of respect in Kaizen led to Toyota adopting a philosophy with 2 pillars-continuous improvement and respect for people (Liker, 2004). Respect for people is seen as core to enabling continuous improvement. To us this is important as it not only respects people but also recognises them as 'moral peers' not merely operatives of drones for care delivery. At this stage of understanding, there is a danger that the philosophy of Kaizen may often be lost in the rush to have continuous improvement and in the application in healthcare. A return to the value of respect for not just people, but person is thus an important link to an integrative approach to person-centred care and Lean Six Sigma. Dewing and McCormack (2015) discuss the importance of knowing both our own, our colleagues, our patients and our organisations values and beliefs. This is important because making values and beliefs clear underpins our work and practice. Dewing and McCormack (2015) see clarity of values and beliefs as a sine qua non for person-centred practice. Working on the person-centred concept of values and beliefs will therefore, to our minds, be an enabler of developing philosophically informed Lean Six Sigma practice in healthcare settings.

\section{The Voice of the Customer}

Lean, Six Sigma and Lean Six Sigma as process improvement methodologies all seek to define what exactly is valuable in a healthcare setting through the perspective of the customer (patient or staff) or end user (Radnor et al., 2012; Williams, 2015; Williams, and Radnor, 2017). The terminology 'Voice of the Customer' is used in Lean Six Sigma to specifically denote customer expectations (Pande et al., 2002; Found and Harrison, 2012). On the one hand, this appears very focused or even contained. However, on the other hand, this is taken to mean improving or creating processes that capture the needs of patients, their families and all hospital staff who interact with the process. Waring and Bishop (2010) suggest understanding what the customer values as the first Lean principle. Yet our review of literature pertaining to the use of Lean Six Sigma in healthcare, similar to that of Found and Harrison (2012) found little attention paid to defining what customer value was or evidence that this actually happens as part of methods; suggesting that this value is espoused only.
Based on the evidence, we further contend that within healthcare, a focus only on the voice of the patient, may ignore or exclude the voice of other customers. We argue this coincides with the tendency for some Lean Six Sigma work to focus more on the macro-organisational customer needs such as efficiency and for persons experiences to become peripheral. Waring and Bishop (2010) perceive that any Lean Six Sigma initiatives should be viewed through the interaction and mediation of the people involved and social structures in which they exist and over time, with which we concur.

In our view, the voice of the customer principle should clarify the definition of the 'customer' to include any person who 'touches' the process, not just the patient and family, so there is no misunderstanding of intent. The involvement of those touching the process has predominantly focused on getting something from the employee (such as more productivity) rather than giving something to the employee (such as opportunities). We find that person-centred approaches focus on and use processes that are much more about offering opportunities much more effectively than Lean Six Sigma. The concepts of authentic engagement (Dewing, 2010; Dewing and McCormack, 2015; 2017), active learning, involving engaging with experience via critical reflection, learning from our practice and evaluation (Dewing, 2010) and human flourishing, which focuses on maximising an individuals potential for development and growth within changing circumstances as an individual, part of a group or community and as a member of society, are central (McCance et al., 2011; McCormack and Titchen, 2014). McCormack and Titchen (2014) suggest that within the contextual settings of contemporary organisations there is recognition that individuals' potential to be 'maximised and realised' has resulted in a greater emphasis on finding conditions that enable people to 'flourish' in their work environments. Theoretically, Lean Six Sigma initiatives are supposed to enable employees to work in an environment that both motivates and sustains (Veech, 2004) thus a focus on this aspect of transformation is an area of synergy between the two methodologies. A Lean Six Sigma study in an Irish hospital (Kieran et al., 2018) focusing on improving processes and efficiency around oral drug round practices exemplifies nursing and pharmacy staff leading on a Lean Six Sigma improvement with consideration for opportunities for improvement to benefit both patients and staff. The project, whilst focusing on the patient as the primary customer, fully engaged with the nursing, pharmacy and portering teams at ward level, in improving the process and reports freeing up six hours per week on the $8 \mathrm{am}$ drug round alone. The time released was directly used in patient care delivery. This more participatory approach to Lean Six Sigma emphasises the role of all the people 
involved in delivering care and illustrates how seeking the Voice of the Customer when fully implemented, aligns more with person-centred approaches, which emphasis finding the time for nurses to listen and talk with their patients (Ross et al., 2015). A further Lean Six Sigma project (Hayden et al., 2016; Feeney et al., 2016) to develop a new stroke pathway had a collaborative, inclusive and participatory approach to improving care, engaging with 200 healthcare staff internal and external to the hospital on 800 occasions to co-design the improved pathway. This resulted in improving the Door-to-Needle time for thrombolysis of stroke patients from 80 to 44 minutes improving patient outcomes and life expectancy. The staff involved worked collaboratively to design a new Stroke Care pathway that whilst benefiting the patient, also made care delivery more efficient for staff via user friendly visual identification systems. Evaluation findings demonstrate that staff embraced the project, with the Clinical Nurse Specialists in Stroke care monitoring patient and staff feedback and the pathway times as part of their role.

Williams (2015) discerned some similarities between patient participation in both Lean Six Sigma and personcentred approaches including understanding value from the voice of the consumer, seeing patient experience as integral, continual improvement in system performance, pursuit of perfection enabling the patient to indicate the resources they need and facilitating the journey of the patient to the next step in the care pathway. Kelly (2013) suggests that the uniqueness of each workforce, organisation and its inherent culture, in our interpretation the 'context' in which care is given, are factors critical to a person-centred care approach; yet are not pre-requisite considerations of Lean Six Sigma before change 'deployment'. Similarly, Curatolo et al. (2014) argue person-centred approaches promote more individualised care, whereas Lean standardises care, with Lean Six Sigma failing to explore the interactions and relationships between people, human behaviour and the work environment; and this is certainly absent in the literature to date. We argue in support of both Kelly and Curatolo, that Lean Six Sigma can be used to have a standardising effect, but also with an individualised focus on both staff and patients involved. While Liker (2004) discusses the importance for Toyota of adapting its culture to local conditions; we are conscious that greater attention is required by Lean Six Sigma initiatives on the importance of 'context' - for example, micro-culture, skill mix, the physical environment and other key variables that always feature in person-centred innovation (McCormack and McCance, 2017). The divergence between theory and what is happening in Lean Six Sigma initiatives points to a need to enhance reporting of how Lean Six Sigma is implemented and possibly for more flexibility in implementation so that local context and culture can be enhanced in sustainable ways; something that is core to personcentredness. Drawing on more person-centred methods has the potential to retain the initial focus on persons within Lean principles.

\section{Conditions for Staff Empowerment}

Dewing and McCormack (2017) state that personcentred cultures offer conditions that enable the staff empowerment needed for authentic engagement in improvements and innovation and in continuous development. A person-centred culture ultimately aims to provide conditions whereby staff can empower themselves to engage in ongoing development and quality enhancement (Dewing and McCormack, 2017) through a variety of workplace learning opportunities. Central to this is the role of workplace facilitation in culture innovation. Person-centred approaches place a high degree of attention on skilled facilitation processes within improvement and innovation initiatives in the workplace (Lynch, 2015; Hardiman and Dewing, 2019). This approach to staff empowerment is echoed in approaches to facilitating use of Lean Six Sigma in healthcare. For example, McNamara and Teeling (2019) discuss the ongoing development of University based Lean Six Sigma healthcare education curricula in Ireland, which locate Lean Six Sigma within conceptual frameworks that emphasise systems thinking and also anchors it to the values on which Lean was founded and avoids reducing Lean Six Sigma to a decontextualized toolkit. Dickson et al. (2008) suggest that healthcare staff relate to Lean Six Sigma better if trained by other healthcare staff who are Lean experts, rather than the usual overreliance on industry consultants. Jones (2017) similarly suggests that staff developments of Lean Six Sigma skills are best 'nurtured and sustained' by other staff members/colleagues acting as mentors or coaches and not by delegating the implementation of Lean to external or internal consultants. Jones (2017) reiterates that Lean Six Sigma skills are learnt through daily practice and not just from classroom training in Lean tools or occasional workshops. We concur with Joosten et al. (2009) who suggest that managers must focus not only on process improvement, but also on developing their staff through support, respect and education, as ultimately it is the staff who will implement any sustainable change process. This concept of respect and support, relates not only to the Lean concepts of Kaizen, but again to the Person-centred concepts of Human Flourishing. We know that when conditions of practice enable individuals in the workplace to feel connected to a meaningful purpose and to others; use their valued competencies; have autonomy and experience loving kindness (Gaffney, 2012), individuals and teams work more creatively and effectively. West and Markiewicz 
(2016) discuss how effective teamworking improves both the quality of care from not just the patient viewpoint, but also have an impact on staff retention, absenteeism and importantly, their wellbeing.

\section{Use of Observational Methods to Explore Practice and Culture}

In working to develop practice in a person-centred way, the use of workplace observations is often used to observe the workplace culture (Dewing and McCormack, 2015). These observations are used to feed back to and discuss improvements with staff. Observations as a method in Lean practice are described as a visit to the 'real place' or where the process or work takes place (Gemba). Gemba walks (Ohno and Bodek, 1988) were designed, like observations in person-centred improvement work to enable staff to stand back from work and process and to observe. Consistent with the philosophy underpinning person-centredness a Gemba walk is not an opportunity for critique or fault finding but an activity always approached from a place of mutual respect and of making thinking better. The processes involved in both approaches to observations are virtually identical and therefore a major synergy between Lean Six Sigma and person-centred care.

\section{Straddling Synergy and Divergence: Quality}

Whilst McCormack and Watson (2018) acknowledge that there is much to applaud in quality improvement initiatives such as the PDSA (Plan, Do, Study, Act) cycle, they query if they actually achieve culture change. Continuous improvement is a key component of any Lean Six Sigma thinking (Womack and Jones, 1996) and continuous improvement along with innovation, both key components of developing person-centred care and cultures (Dewing and McCormack, 2015). Thus there appears a synergy. However, within our review we found that there is a point of divergence for discussion also.

Lean Six Sigma similar to person-centred approaches has a focus on continuous quality improvement. Lean Six Sigma certainly has a number of methods and tools for identifying the Voice of the Customer, for example the Critical to Quality (CTQ) tree. The CTQ is used to identify the needs of the customer (e.g. patients, staff, family), identify what drivers the organisation should have in place to meet these needs and identify the metrics to ensure that this driver is delivering on the need. Thus, it is designed to capture the key measurable characteristics of a process, or service whose performance standards must be met in order to satisfy the customer (Rath and Strong, 2002). Methods to understand customer and stakeholder experiences are also found in programmes aimed at enhancing personcentred cultures and care (Dewing and McCormack, 2015). However, we suggest, at present, there exists theoretical and methodological divergence on core concepts such as voice, experience, metrics and measuring between the two approaches and therefore see Quality as currently straddling both.

\section{Divergence}

What is evident to us from our review at a macro level is that divergences between both methodologies are not located in the literature. This leaves an identifiable gap in the empirical evidence for any staff attempting to introduce process improvement using Lean Six Sigma in an environment that espouses to deliver person-centred care. It is significant that within our work to date we have identified three key areas of divergence that can inform staff who use or wish to use both methodological approaches within their practice areas.

\section{Core Values}

A key divergence between Lean Six Sigma and Person-centred approaches lies within the understanding of 'core values' and how significant this might be. Williams (2015) notes that value is seen in a wider context in person-centred care with a focus on patients, families and staff and social values, whereas Lean focuses on improvement processes. We concur with Williams that this wider social value could be excluded if the haste for process improvement does not occur incrementally and with staff inclusion. However, we have discussed how respect is linked to value and we suggest that Lean Six Sigma use does not necessarily negate social value inclusion in its scope of practice. We suggest that this speaks to 'how' we as healthcare practitioners use Lean Six Sigma, which could be adapted, as we have tried to do in our own clinical practice, to a person-centred culture approach. Indeed Williams (2015) argues that if Lean were implemented focusing on efficiencies alone it would be at odds with its main principles, quality improvement and creating value for the customer i.e., all those involved in patient care, highlighting that value is a key element in both Lean Six Sigma and person-centred care. Understanding the difference between Lean Six Sigma value to the customer and the concept of values as a way of life (McCormack and McCance, 2017) is important in developing this synergy of value. Seeking the patient's perspective and adding the voice of family and carers can add strength to the development of processes and procedures that are built with the patient at the centre.

We note this important divergence between both methodologies but suggest that by realigning Lean Six Sigma with its origins and combining it with new knowledge on how person-centred cultures can be achieved that there is the potential to build health care systems that are based on patients' and practitioners' values, develop environments where the flow of patients, 
materials and information is seamless and in which a culture of continuous improvement that includes patients and families as shared decision makers thrives. Interestingly, 'Kaizen' the Japanese concept of continuous improvement, slow, incremental and constant might be a useful meeting or convergence point between both approaches. Kaizen in its broadest sense, is more often viewed as being about good change rather than better change; and is applied to personal, home, social and working life (Imai, 1986) and seen by some as a philosophy of life (Imai, 1986; Wittenberg, 1994). From this latter perspective, the Japanese kanji for "change" is made of two characters meaning "self" and "whip". This is literally interpreted as having to whip ourselves to create new habits. A broader interpretation is that change starts within each of us and requires us to have commitment to the process; thus we must have the self-discipline to follow through and create the change. In contrast, personcentredness advocates creating conditions for human flourishing, where change can occur when the conditions are right for the individual and change is driven by the person's values and beliefs and is essentially a social learning based process. While it is recognised that such change needs to be systematic and one that too requires discipline, person-centred approaches pay distinct attention to individuals' whole self and recognises that the rate of change is determined by each individual, influenced by many variables including their context, interpreting self and context as two entities that are inseparably entwined.

\section{Standardisation}

Langabeer et al. (2009) argues that by standardising processes we limit healthcare professionals' decisionmaking and autonomy and thereby hinder their ability to provide safe and effective care. Morgan and Yoder (2012) suggest that person-centred care incorporates four characteristics, which are: holistic, individualised, respectful and empowering. The standardisation that comes from Lean Six Sigma initiatives can be difficult to tailor to individual patients, rather than groups and projects specific to individual patients rather than groups of patients have yet to be examined. In healthcare, there are instances where diversity in care approaches enables staff to meet the needs of individual patients (Saurin et al. 2013) and Lean Six Sigma must make allowances for this. We contend that in Lean Six Sigma there is a predominant focus on standardisation informed by evidence whereas the predominant focus on personalisation of services, informed by multiple sources of evidence including patient preference is evident in person-centredness. There is a need to combine both to achieve efficiency and to preserve autonomy of both staff and patients and families.

\section{First Principles}

Approaches in Lean Six Sigma have as a first principle the concept of understanding Value (Williams, 2015). Person-centred Care has a prerequisite stage to assess professional competence, commitment to practice and clarity of beliefs and values (Williams, 2015). According to McCormack et al. (2015), an organisation that is person-centred would have the following attributes:

- A caring approach to how we meet needs

- Nurtures effective relationships

- Promotes social belonging

- Creates meaningful spaces and places

- Promotes human flourishing

A move to understand and work within the beliefs and values of the staff leading on Lean Six Sigma initiatives, not just the patients and staff they are working with, would in our opinion give increased consideration to the complexity of the social interactions and empower Lean Six Sigma practitioners and students to facilitate meaningful change in not only processes but patterns that exist and support or challenge best practice in workplace cultures.

Lean Six Sigma has been used in the Universities for process improvement in areas including admissions, registration, management, business and research functions (Hess and Benjamin, 2015) however with the exception of 1 paper (McNamara and Teeling, 2019) there is no evidence of or discussion of Lean Six Sigma teaching methods for healthcare evident in the literature. Person-centred methods with an emphasis on workplace learning may have some synergy with Lean Six Sigma work based projects, but the teaching methods within person-centredness promote experiential, whole person learning and are useful for educators who go into different care settings (Dewing and McCormack, 2015). This is an area we continue to work on in our own practice in developing person-centred models for Lean Six Sigma delivery.

\section{Implications for Nursing}

We have discussed core synergies and divergences in relation to Lean Six Sigma and person-centredness. We believe that staff awareness of these synergies (Fig. 2) could be worked on to lead to an integrative approach to Lean Six Sigma use through a personcentred care approach and that the divergences (Fig. 2) could likewise be worked on to narrow the gap and more closely align Lean Six Sigma with the development of person-centred cultures. 


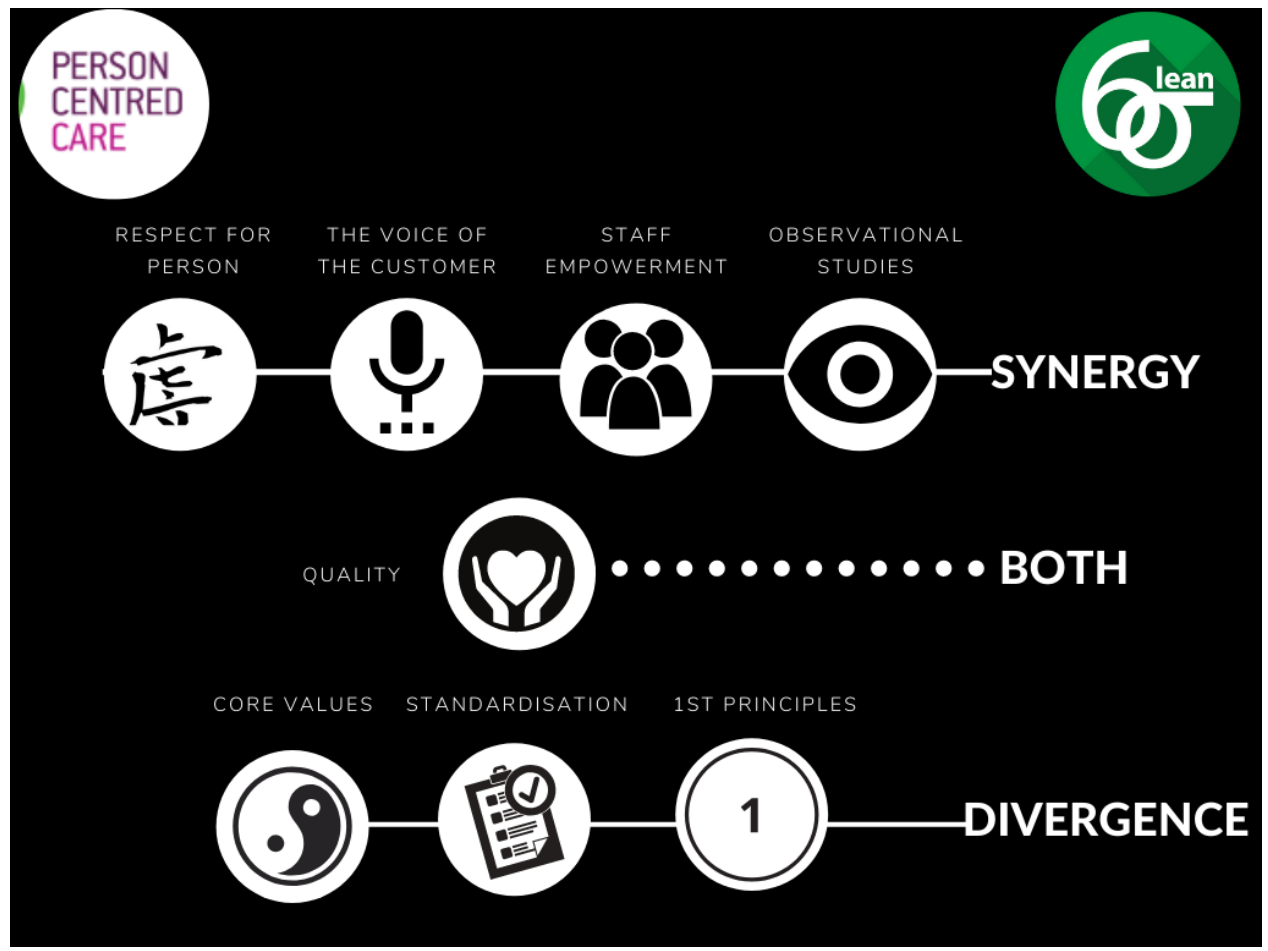

Fig. 2: Synergies and divergences between Lean Six Sigma and Person-centredness (Teeling et al., 2020)

Dewing and McCormack (2015; 2017) state that service improvement (which is what Lean Six Sigma ultimately is) has what they term 'person-centred moments' yet is not a fully realised person-centred culture, which in our opinion corroborates our findings on synergies and divergence. Our exploration of the philosophies underpinning Lean Six Sigma and personcentredness indicate too that Lean Six Sigma does have some important person-centred features. Work to date suggests however that there are further research and practice changes needed to enhance the synergies, narrow the gaps and to reconcile areas of divergence. The current lack of empirical evidence supporting the integration of Lean Six Sigma and person-centred care highlights the need for further exploration of the conceptual bases of these approaches. Some preliminary work on managing the dichotomy has been put forward by adapting value stream design to incorporate individualised customisation (Naim and Gosling, 2011). However, we concur with Stirk and Sanderson (2012) who advised that Lean, Six Sigma and Lean Six Sigma are valuable continuous improvement tools which are not out of place in a person-centred organisation, which has a continual focus on the people whom the organisation supports and on community contribution (Williams and Sanderson, 2003). Drucker (1993) suggests that healthcare organisations are the most complex form of human organisation, with complexity deriving from the confluence of professions (e.g., doctors, nurses, health and social care professions) and other stakeholders (e.g., patients, relatives, corporate functions) frequently with seemingly incompatible perspectives and timelines. Into this context add Lean Six Sigma as the process improvement methodology of choice, then the important role of person-centredness in drawing attention to the relational aspects of care between patients, families and professionals becomes evident.

\section{Limitations}

We found a lack of published research studies specific to the use of both Person-centred and Lean Six Sigma methodologies to draw on for the review that underpinned this discussion article. We chose to focus on synergies and divergences and may have overlooked other important themes that need discussion. Further, we also selected a small number of synergies and divergences to discuss in this article, which may skew the bigger picture understanding of Lean Six Sigma methodologies or personcentred approaches.

\section{Conclusion}

We conclude that there is some synergy between some ideas within Lean, Six Sigma, Lean Six Sigma and person-centredness that need further study. More often however, these lie at the philosophical level and are less evident in the actual practice application of Lean Six Sigma. Changing workplace patterns and processes is 
dependent on the 'human factor'. It is our belief that if Lean Six Sigma is about service improvement, then to be truly person-centred this improvement must involve not just staff, but patients and their family in the evaluation of current and design of new care pathways. To move it towards being a method for continuous quality improvement and thus influence at the cultural as well as the practical level it must fully engage the 'voice' of staff and patients to discover what is 'critical' to them in designing, delivering or receiving care.

The synergies we have found go some way to dispelling a current narrative that Lean Six Sigma and person centred improvement approaches are polar opposite in their underlying philosophies, intentions, methods and outcomes. That said, divergences do exist and little work has been undertaken to date to explore or address these. We propose that the synergies identified provide a firm foundation for new and innovative models of Lean Six Sigma that can enhance efficiency and transform person-centred cultures. We recognise that divergence is mainly at the level at which Lean Six Sigma is implemented and where it has become removed from its original underpinning philosophy. As such we suggest that there is need for further work and research on aligning both Lean Six Sigma and person-centred approaches within improvement sciences, to maximise its contribution in the health care context.

- Conflict of interest statement: "No conflict of interest has been declared by the author(s)"

- Funding statement: "This paper was supported by Queen Margaret University Edinburgh and University College Dublin"

- The authors acknowledge the ongoing support of Mary Day, CEO Ireland East Hospital Group in this research

\section{Author's Contributions}

Seán Paul Teeling: Contributed to literature review, findings, discussion, conclusions and graphics.

Jan Dewing and Deborah Baldie: Contributed to literature review, findings, discussion, and conclusions.

\section{Ethics}

This article is original and contains unpublished material. The corresponding author confirms that all of the other authors have read and approved the manuscript and no ethical issues involved.

\section{Reference}

Abu Bakar, F.A., K. Subari and M.A. Mohd Daril, 2015. Critical success factors of Lean Six Sigma deployment: A current review. Int. J. Lean Six Sigma, 6: 339-348. DOI: 10.1108/IJLSS-04-2015-0011
Aherne, J. and J. Whelton, 2010. Applying Lean in Healthcare: A Collection of International Case Studies. 1st Edn., Productivity Press, New York, ISBN-10: 1439827397, pp: 247.

Antony, J., 2007. Six Sigma: A strategy for supporting innovation in pursuit of business excellence invited paper. Int. J. Technol. Manage., 37: 8-12.

Ballé, M. and A. Régnier, 2007. Lean as a learning system in a hospital ward. Leadership Health Services, 20: 33-41.

Berwick, D., 2015. Era 3: Foundational values for a sound future. Keynote address, IHI, National Forum.

Bisgaard, S. and J. Freiesleben, 2000. Economics of Six Sigma programs. Quality Eng., 13: 325-331.

Black, J., 2009. Transforming the patient care environment with LSS and realistic evaluation. J. Healthcare Quality, 31: 29-35. DOI: $10.1111 /$ j.1945-1474.2009.00028.x

Burgess, N. and Z. Radnor, 2013. Evaluating lean in healthcare. Int. J. Health Care Quality Assurance, 26: 220-235. DOI: 10.1108/09526861311311418

Colldén, C., I. Gremyr, A. Hellström and D. Sporraeus, 2017. A value-based taxonomy of improvement approaches in healthcare. J. Health Organiz. Manage., 31: 445-458. DOI: 10.1108/JHOM-08-2016-0162

Collins, K.F. and S.K. Muthusamy, 2007. Applying the Toyota production system to a healthcare organisation: A case study on a rural community healthcare provider. Quality Manage. J., 14: 41-52.

Cookson, D., C. Read, P. Mukherjee and M. Cooke, 2011. Improving the quality of Emergency Department care by removing waste using Lean Value Stream mapping. Int. J. Clin. Leadership, 17: 25-30.

Creed, M., McGuirk, M., Buckley, R., Kilduff, M. (2019) 'Using Lean Six Sigma to improve controlled drug processes and release nursing time', J. Nurs. Quality, 34: 236-241. DOI: $10.1097 / \mathrm{NCQ} .0000000000000364$

Curatolo, N., S. Lamouri and H.A. Rieutord, 2014. A critical analysis of Lean Approach structuring in hospitals. Bus. Proc. Manage. J., 20: 433-454.

De Souza, B.L., 2009. Trends and approaches in lean healthcare. Leadership Health Services, 22: 121-139. DOI: 10.1108/BPMJ-04-2013-0051

Deblois, S. and L. Lepanto, 2016. Lean and Six Sigma in acute care: A systematic review of reviews. Int. J. Health Care Quality Assurance, 29: 192-208.

Dewing, J. and B. McCormack, 2015. Engagement: A critique of the concept and its application to personcentred care. Int. J. Practice Dev.

Dewing, J. and B. McCormack, 2016. Tell me, how do you define person-centredness?. J. Clin. Nurs. Accepted Author Manuscript, 26: 2509-2510. DOI: $10.1111 /$ jocn. 13681 
Dewing, J. and B. McCormack, 2017. Creating Flourishing Workplaces. In: Person-Centred Nursing, McCormack, B. and T. McCance (Eds.), Oxford Wiley-Blackwell.

Dewing, J., 2010. Moments of movement: Active learning and practice development. Nurse Educ. Practice, 10: 22-26.

DO: $10.1108 / 17511870910953788$

Dickson, E.W., S. Singh, D.S. Cheung, C.C. Wyatt, and A.S. Nugent, 2008. Application of Lean manufacturing techniques in the emergency department. J. Emergency Med., 37: 1177-182.

Drucker, P.F., 1993. Post-Capitalist Society. 1st Edn., Harper Business, New York, ISBN-10: 0887306209, pp: 232.

Dunsford, J. and L.E. Reimer, 2017. Relationshipcentered health care as a Lean intervention. Int. J. Quality Health Care, 29: 1020-1024.

DOI: $10.1093 /$ intqhe/mzx156

Edvardsson, D., D. Fetherstonhaugh and R. Nay, 2010. Promoting a continuation of self and normality: Person-centred care as described by people with dementia, their family members and aged care staff. J. Clin. Nurs., 19: 2611-2618.

DOI: $10.1111 / \mathrm{j} .1365-2702.2009 .03143 . x$

Feeney, A., T. Barry, D. Hayden, L. Higgins, and E. Kavanagh et al., 2016. Pre-hospital fast positive cases identified by DFB ambulance paramedics: Final clinical diagnosis. Irish Med. J., 109: 397-397.

Fillingham, D., 2008. Lean Healthcare: Improving the Patient's Experience. Kingsham Press, United Kingdom.

Found, P. and R. Harrison, 2012. Understanding the lean voice of the customer. Int. J. Lean Six Sigma, 3: 251-267. DOI: 10.1108/20401461211282736

Gaffney, M., 2012. Flourishing: How to Achieve a Deeper Sense of Well-being, Meaning and Purpose Even when Facing Adversity. Penguin, London.

George, M.L., D. Rowlands, M. Price and J. Maxey, 2005. The Lean Six Sigma Pocket Tool book. 1st Edn., McGraw-Hill, New York, ISBN-10: 9789352603527, pp: 225.

Guimarães, C.M. and J.C. De Carvalho, 2012. Lean healthcare across cultures: State-of-the-art. Am. Int. J. Contemporary Res., 2: 187-206.

Hardiman, M. and J. Dewing, 2019. Using two models of workplace facilitation to create conditions for development of a person-centred culture: A participatory action research study. J. Clin. Nurs., 28: 2769-2781. DOI: 10.1111/jocn.14897

Hayden, D., C. Byrne, L. Higgins, M. O'Reilly and S.P. Teeling et al., 2016. Lean Six Sigma: A highly effective approach to reducing door-to-needle times in acute ischemic stroke. Int. J. Stroke.
Hess, J.D. and B.A. Benjamin, 2015. Applying Lean Six Sigma within the university: Opportunities for process improvement and cultural change. Int. J. Lean Six Sigma, 6: 249-262.

ICN, 2019. Strategic Priorities-Person centred care. ICN. Imai, M., 1986. Kaizen-the key to Japan's competitive success. Random House, New York.

Johnston, M.E., 2013. Organizational effectiveness employing a lean team leadership structure in health care: A case study. ProQuest Dissertations Publishing.

Jones, D., 2017. Dan Jones shares four lessons on lean healthcare reducing waste and errors: Piloting lean principles at Intermountain healthcare methods, tools and strategies.

Joosten, T., I. Bongers, and R. Janssen, 2009. Application of lean thinking to health care: Issues and observations. Int. J. Quality Health Care, 21: 341-347.

Jorma, T., H. Tiirinki, R. Bloigu and L. Turkki, 2016. Lean thinking in Finnish healthcare. Leadership Health Services, 29: 9-36. DOI: 10.1108/LHS-08-2015-0021

Kelly, J., 2013. The effect of lean systems on personcentred care. Nurs. Times, 109: 16-17.

Kieran, M., M. Cleary, A. De Brún and A. Igoe, 2018. Supply and Demand: Application of Lean Six Sigma methods to improve drug round efficiency and release nursing time. Oxford University Press.

Langabeer, J.R., J.L. DelliFraine, J. Heineke and I. Abbass, 2009. Implementation of Lean and Six Sigma quality initiatives in hospitals: A goal theoretic perspective. Oper. Manage. Res., 2: 13-27. DOI: $10.1007 / \mathrm{s} 12063-009-0021-7$

Li, J. and D. Porock, 2014. Resident outcomes of personcentered care in long-term care: A narrative review of interventional research. Int. J. Nurs. Studies, 51: 1395-1415. DOI: 10.1016/j.ijnurstu.2014.04.003

Liker, J., 2004. The Toyota Way. 1st Edn., Simon and Schuster, New York, ISBN-10: 0070587477, pp: 69.

Lynch, B., 2015. Partnering for performance in situational leadership: A person-centred leadership approach. Int. Practice Dev. J., 5: 1-10. DOI: $10.19043 /$ ipdj.5SP.007

Manley, K. and B. McCormack, 2008. Person-centred care. Nursing Manage., 15: 12-13. DOI: $10.7748 / \mathrm{nm} 2008.12 .15 .8 .12 . c 6874$

Marriott-Statham, K., M. Mackay, J. Mackay and N. Brennan, 2018. Empowering aged care nurses to deliver person-centred care: Enabling nurses to shine. Nurse Educ. Practice, 31: 112-117. DOI: 10.1016/j.nepr.2018.05.014

Mazzocato, P., C. Savage, M. Brommels, H. Aronsson, and J. Thor, 2010. Lean thinking in healthcare: A realist review of the literature. Quality Safety Health Care, 19: 376-382. 
Mazzocato, P., J. Thor, U. Backman, M. Brommels and J. Carlsson et al., 2014. Complexity complicates lean: lessons from seven emergency services. J. Health Organis. Manage., 28: 266-288. DOI: 10.1108/JHOM-03-2013-0060

McCance, T., B. McCormack, and J. Dewing, 2011. Exploration of person-centeredness in practice. Online J. Issues Nurs.

McConnell, K.J., R.C. Lindrooth, D.R. Wholey, T.M. Maddox and N. Bloom, 2013. Management practices and the quality of care in cardiac units. JAMA Internal Med., 173: 684-692.

DOI: 10.1001/jamainternmed.2013.3577

McCormack, B. and A. Titchen, 2014. No beginning, no end: An ecology of human flourishing. Int. Practice Dev. J.

McCormack, B. and R. Watson, 2018. Values, virtues and initiatives-time for a conversation. J. Adv. Nurs., 74: 753-754. DOI: 10.1111/jan.13352

McCormack, B. and T. McCance, 2017. Person-Centred Practice in Nursing and Healthcare: Theory and Practice. 2nd Edn., John Wiley and Sons, ISBN-10: 1118990560, pp: 286.

McCormack, B. and T. McCance, 2017. Person-Centred Practice in Nursing and Healthcare: Theory and Practice. 2nd Edn., Wiley-Blackwell, Chichester, ISBN-10: 1118990560, pp: 286.

McCormack, B., 2003. A conceptual framework for person-centred practice with older people. Int. J. Nurs. Pract., 9: 202-209.

DOI: $10.1046 / \mathrm{j} .1440-172 X .2003 .00423 . x$

McCormack, B., 2015. Seeking a Person Centred culture. Scottish Government, St. Andrew's House, Regent Road, Edinburgh EH1 3DG, Scotland.

McCormack, B., J. Dewing, L. Breslin, A. Coyne-Nevin and K. Kennedy et al., 2010. Developing personcentred practice: Nursing outcomes arising from changes to the care environment in residential settings for older people. Int. J. Older People Nurs., 5: 93-107. DOI: 10.1111/j.1748-3743.2010.00216.x

McCormack, B., K. Manley, and A. Titchen, 2013. Practice Development in Nursing and Healthcare. 2nd Edn., Wiley-Blackwell, Chichester, West Sussex, ISBN-10: 1118448782, pp: 320.

McCormack, B., M. Borg, S. Cardiff, J. Dewing and G. Jacobs et al., 2015. Person-centredness - the 'state' of the art. Int. Practice Dev. J., 5: 1-15.

McMillan, S.S., E. Kendall, A. Sav, M.A. King and J.A. Whitty et al., 2013. Patient-centered approaches to health care: A systematic review of randomized controlled trials. Med. Care Res. Rev.

McNamara, M., Teeling, S.P. 2019. Developing a university-accredited Lean Six Sigma curriculum to overcome system blindness. Int. J. Quality Healthcare, 31: 3-5. DOI: 10.1093/intqhc/mzz074
Mead, N. and P. Bower, 2002. Patient-centred consultations and outcomes in primary care: A review of the literature. Patient Educ. Couns., 48: 51-61. DOI: 10.1016/S0738-3991(02)00099-X

Moore, L., N. Britten, D. Lydahl, Ö. Naldemirci and M. Elam et al., 2016. Barriers and facilitators to the implementation of person-centred care in different healthcare contexts. Scandinavian J. Car. Sci.

Moraros, J., M. Lemstra and C. Nwankwo, 2016. Lean interventions in healthcare: Do they actually work? A systematic literature review. Int. J. Quality Health Care, 28: 150-165. DOI: 10.1093/intqhc/mzv123

Morgan, S. and L.H. Yoder, 2012. A concept analysis of person-centered care. J. Holistic Nurs., 30: 6-15. DOI: $10.1177 / 0898010111412189$

Naim, M. and J. Gosling, 2011. On leanness, agility and leagile supply chains. Int. J. Product. Economic, 13: 342-354.

Nelson-Peterson, D.L. and C.J. Leppa, 2007. Creating an environment for caring using lean principles of the Virginia Mason production system. JONA: J. Nurs. Admin., 37: 287-294.

Nicosia, F.M., L.G. Park, C.P. Gray, M.J. Yakir and D.Y. Hung, 2018. Nurses' perspectives on lean redesigns to patient flow and inpatient discharge process efficiency. Global Qualitative Nursing Res., 5: $2333393618810658-2333393618810658$. DOI: $10.1177 / 2333393618810658$

Nolte, E., 2017. Editorial. BMJ, 358: j4126-j4126.

O’Hora, L., J. Stanley, L. Fox and K. Murphy, 2015. An investigation of the effectiveness of Lean Six Sigma strategies in reducing computed tomography order to report time. Radiography Ireland, 18: 13-17.

O’Neill, S., T. Jones, D. Bennett and M. Lewis, 2011. Nursing works: The application of lean thinking to nursing processes. J. Nurs. Admin., 41: 546-552.

Ohno, T. and N. Bodek, 1988. The Toyota production system: Beyond large-scale production. Productivity Press.

Pande, P.S., R.P. Neuman and R.R. Cavanagh, 2002. The Six Sigma Way team fieldbook: An implementation guide for process improvement. McGraw-Hill, New York.

Powell, A., R. Rushmer and T.O. Huw Davies, 2009. A systematic narrative review of quality improvement models in health care. Engineering.

Radnor, Z. and S. Osborne, 2013. Lean: A failed theory for public services? Public Manage. Rev., 15: 265-287. DOI: 10.1080/14719037.2012.748820

Radnor, Z., M. Holweg, and J. Waring, 2012. Lean in healthcare: The unfilled promise? Soc. Sci. Med., 74: 364-71.

Rath and Strong, 2002. Six Sigma pocket guide. McGraw-Hill, New York. 
Ross, H., A.M. Tod, and A. Clarke, 2015. Understanding and achieving person-centred care: The nurse perspective. J. Clin. Nurs., 24: 1223-1233.

Saurin, T.A., J. Rooke, and L. Koskela, 2013. A Complex systems theory perspective of lean production. Int. J. Product. Res., 51: 5824-5838.

Stirk, S. and H. Sanderson, 2012. Creating personcentred organisations: Strategies and tools for managing change in health, social care and the voluntary sector. Jessica Kingsley Publishers, London, Philadelphia.

Suárez-Barraza, M.F., J. Ramis-Pujol, L. Kerbache, 2011. Thoughts on kaizen and its evolution three different perspectives and guiding principles. Int. J. Lean Six Sigma, 2: 288-308. DOI: $10.1108 / 20401461111189407$

Teeling, S.P., H. Coetzee, M. Phillips, M. McKiernan, and É. Ní She et al., 2019. Reducing risk of development or exacerbation of nutritional deficits by optimizing patient access to mealtime assistance. Int. J. Quality Healthcare, 31: 6-13.

Teichgräber, U.K. and M. de Bucourt, 2012. Applying value stream mapping techniques to eliminate nonvalue-added waste for the procurement of endovascular stents. Eur. J. Radiol., 81: e47-e52.

Tolga Taner, M., B. Sezen and J. Antony, 2007. An overview of six sigma applications in healthcare industry. Int. J. Health Care Quality Assurance, 20: 329-340. DOI: 10.1108/09526860710754398

Veech, D.S., 2004. A person-centered approach to sustaining a lean environment-job design for selfefficacy. Office of the Under Secretary of Defence for Acquistion Technology and Logistics, Washington DC.

Vijaya Sunder, M., 2013. Synergies of lean Six Sigma. IUP J. Operat. Manage., 12: 21-31.

Waring, J.J. and S. Bishop, 2010. Lean healthcare: Rhetoric, ritual and resistance. Soc. Sci. Med., 71: 1332-1340.

West, M.A. and L. Markiewicz, 2016. Effective team Work in Health Care. In: The Oxford Handbook of Health Care Management, Ferlie, E. (Ed.), Oxford University Press, pp: 231-252.

Williams, R. and H. Sanderson, 2003. What are we learning about person-centred organisations?

Williams, S., 2015. Lean and person-centred care: Are they at odds?

Wittenberg, G., 1994. Kaizen - The many ways of getting better. Assembly Automation, 14: 12-12.

Womack. J and D. Jones, 1996. Lean thinking: Simon and Schuster. New York.
Yeh, H.L., C.S. Lin, C.T. Su and P.C. Wang, 2011. Applying LSS to improve healthcare: An empirical study. African J. Bus. Manage., 5: 12356-12370.

Zidel, T.G., 2006. A Lean Guide to Transforming Healthcare: How to Implement Lean Principles in Hospitals, Medical Offices, Clinics and Other Healthcare Organisations. 1st Edn., ASQ, Quality Press, Milwaukee, ISBN-10: 0873898990, pp: 192.

\section{What is Already Known about the Topic?}

- Improvement science based approaches are not often drawn on in person-centred research

- There is little research literature on how Lean Six Sigma and person-centred approaches might work together

- There is limited evidence of the synergies between Lean Six Sigma and person-centred approaches in healthcare

\section{What this Paper Adds}

- We have found four key synergies and three key divergences between Lean Six Sigma and personcentred improvement sciences

- We indicate where synergies can be maximised and divergence narrowed to improve implementation and enhance methodological coherence

- We raise awareness for researchers, policy makers and practitioners that use of Lean Six Sigma alone may have a limited impact on developing personcentred care and culture 